This item was submitted to Loughborough's Research Repository by the author.

Items in Figshare are protected by copyright, with all rights reserved, unless otherwise indicated.

\title{
Intranasal delivery of bone marrow derived mesenchymal stem cells, macrophages, and microglia to the brain in mouse models of Alzheimer's and Parkinson's disease
}

\section{PLEASE CITE THE PUBLISHED VERSION}

http://dx.doi.org/10.3727/096368914X684970

\section{PUBLISHER}

(C) 2014 Cognizant Communication Corporation

\section{VERSION}

VoR (Version of Record)

\section{PUBLISHER STATEMENT}

This work is made available according to the conditions of the Creative Commons Attribution-NonCommercial 3.0 International (CC BY-NC 3.0) licence. Full details of this licence are available at: https://creativecommons.org/licenses/by-nc-nd/3.0/

\section{LICENCE}

CC BY-NC-ND 3.0

\section{REPOSITORY RECORD}

Danielyan, Lusine, Sandra Beer-Hammer, Alexandra Stolzing, Richard Schafer, Georg Siegel, Claire Fabian, Philipp Kahle, et al.. 2019. "Intranasal Delivery of Bone Marrow Derived Mesenchymal Stem Cells, Macrophages, and Microglia to the Brain in Mouse Models of Alzheimer's and Parkinson's Disease". figshare. https://hdl.handle.net/2134/16424. 


\title{
Intranasal Delivery of Bone Marrow-Derived Mesenchymal Stem Cells, Macrophages, and Microglia to the Brain in Mouse Models of Alzheimer's and Parkinson's Disease
}

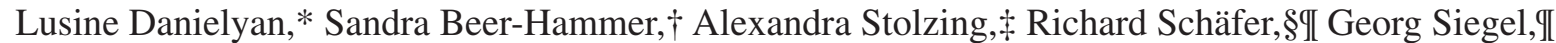
Claire Fabian, $\$$ Philipp Kahle,\# Tilo Biedermann, ${ }^{* *}$ Ali Lourhmati, $*$ Marine Buadze, $*$ Ana Novakovic, $\dagger$ Barbara Proksch,* Christoph H. Gleiter,* William H. Frey II, $\dagger \dagger$ and Matthias Schwab* $+\neq$

*Department of Clinical Pharmacology, Eberhard Karls University Hospitals and Clinics, and Interfaculty Center of Pharmacogenomics and Drug Research, University of Tübingen, Tübingen, Germany $†$ Department of Pharmacology and Experimental Therapy, Institute of Experimental and Clinical Pharmacology and Toxicology, Eberhard Karls University Hospitals and Clinics, and Interfaculty Center of Pharmacogenomics and Drug Research,

University of Tübingen, Tübingen, Germany

\$Department of Cell Therapy Stem Cell Biology and Regeneration Unit,

Fraunhofer Institute for Cell Therapy and Immunology, Leipzig, Germany

$\S$ Department Cell Therapeutics and Cell Processing, Institute for Transfusion Medicine and Immunohaematology, German Red Cross Blood Donor Service Baden-Württemberg-Hesse gGmbH, Johann Wolfgang Goethe University Hospital, Frankfurt, Germany

IIInstitute for Clinical and Experimental Transfusion Medicine (IKET,) University Hospital of Tübingen, Tübingen, Germany \#Department of Neurodegeneration, Hertie Institute for Clinical Brain Research and German Center for Neurodegenerative Diseases, Faculty of Medicine, University of Tübingen, Tübingen, Germany

**Department of Dermatology, Eberhard Karls University Tübingen, Tübingen, Germany

††Alzheimer's Research Center, HealthPartners Center for Memory and Aging, Regions Hospital, St. Paul, MN, USA $\$ \neq D$. Margarete Fischer-Bosch Institute of Clinical Pharmacology, University of Tübingen, Stuttgart, Germany

\begin{abstract}
In view of the rapid preclinical development of cell-based therapies for neurodegenerative disorders, traumatic brain injury, and tumors, the safe and efficient delivery and targeting of therapeutic cells to the central nervous system is critical for maintaining therapeutic efficacy and safety in the respective disease models. Our previous data demonstrated therapeutically efficacious and targeted delivery of mesenchymal stem cells (MSCs) to the brain in the rat 6-hydroxydopamine model of Parkinson's disease (PD). The present study examined delivery of bone marrow-derived MSCs, macrophages, and microglia to the brain in a transgenic model of PD [(Thy1)$\mathrm{h}[\mathrm{A} 30 \mathrm{P}] \alpha \mathrm{S}]$ and an APP/PS1 model of Alzheimer's disease (AD) via intranasal application (INA). INA of microglia in naive BL/6 mice led to targeted and effective delivery of cells to the brain. Quantitative PCR analysis of eGFP DNA showed that the brain contained the highest amount of eGFP-microglia (up to $2.1 \times 10^{4}$ ) after INA of $1 \times 10^{6}$ cells, while the total amount of cells detected in peripheral organs did not exceed $3.4 \times 10^{3}$. Seven days after INA, MSCs expressing eGFP were detected in the olfactory bulb (OB), cortex, amygdala, striatum, hippocampus, cerebellum, and brainstem of (Thy1)-h[A30P] $\alpha \mathrm{S}$ transgenic mice, showing predominant distribution within the OB and brainstem. INA of eGFP-expressing macrophages in 13-month-old APP/PS1 mice led to delivery of cells to the OB, hippocampus, cortex, and cerebellum. Both MSCs and macrophages contained Iba-1-positive population of small microglia-like cells and Iba-1-negative large rounded cells showing either intracellular amyloid $\beta$ (macrophages in APP/PS1 model) or $\alpha$-synuclein [MSCs in (Thy1)-h[A30P] $\alpha \mathrm{S}$ model] immunoreactivity. Here, we show, for the first time, intranasal delivery of cells to the brain of transgenic PD and AD mouse models. Additional work is needed to determine the optimal dosage (single treatment regimen or repeated administrations) to achieve functional improvement in these mouse models with intranasal microglia/macrophages and MSCs. This manuscript is published as part of the International Association of Neurorestoratology (IANR) special issue of Cell Transplantation.
\end{abstract}

Key words: Intranasal; Mesenchymal stem cells (MSCs); Macrophages; Alzheimer's disease; Parkinson's disease; Amyloid beta $(\mathrm{A} \beta)$

Received January 25, 2014; final acceptance September 24, 2014. Online prepub date: October 9, 2014.

Address correspondence to Lusine Danielyan, Department of Clinical Pharmacology, Eberhard Karls University Hospitals and Clinics and Interfaculty Center of Pharmacogenomics and Drug Research, University of Tübingen, Auf der Morgenstelle 8, D-72076 Tübingen, Germany. Tel: +49 (0) 70712974926; Fax: +49 (0) 7071295035; E-mail: lusine.danielyan@ @ed.uni-tuebingen.de 


\section{INTRODUCTION}

Surgical transplantation of therapeutic cells into the brain is a commonly used method of cell application for cell-based therapy of neurodegenerative disorders. However, this delivery method is associated with several issues, such as 1) graft rejection problems resulting from immunological responses $(43,63) ; 2)$ consequences of direct tissue trauma, such as inflammation, cerebral edema, and reactive gliosis $(27,53,57)$; and 3 ) difficulties in repeating cell administration due to invasiveness of the method when a single administration does not result in the desired level of improvement. Insufficient graft survival after transplantation has been shown in a model of Parkinson's disease (PD) and in the brains of normal rodents $(6,14,15)$. In the study of Camp et al. (11), failure of mesenchymal stem cells (MSCs) to prevent nigrostriatal dopamine depletion and behavioral deficits in the rat 6-hydroxydopamine (6-OHDA) model of PD was at least partially ascribed to the tissue damage resulting from the surgical transplantation procedure.

Intravenous (IV) application of cells is another method frequently used for cell-based therapies of central nervous system (CNS) disorders. Despite its noninvasiveness and therapeutic successes shown in different models of CNS diseases, such as experimental autoimmune encephalomyelitis (EAE), ischemia, traumatic brain injury, and amyotrophic lateral sclerosis (ALS) $(10,40,73)$, IV delivery is associated with systemic distribution and homing of cells to peripheral organs $(44,56,65)$, pulmonary microvasculature entrapment, and lack of significant cell engraftment in the brain parenchyma $(32,58,72)$. Moreover, a recent study by Yang et al. showed that intra-arterial (IA) delivery is not superior to IV delivery of autologous bone marrow mononuclear cells to the brain in the rat acute ischemic stroke model. The number of cells delivered to the ischemic area did not significantly differ between the IV and IA groups and was below $0.001 \%$ of applied cells (78).

Our previously published work demonstrated that noninvasive intranasal application (INA) of bone marrowderived MSCs results in delivery of numerous stem cells to different brain areas of healthy rodents and of the rat 6-OHDA model of PD, including the olfactory bulb $(\mathrm{OB})$, cortex, and striatum $(20,21)$. Out of $1 \times 10^{6}$ intranasally delivered MSCs, $2.4 \times 10^{5}$ were detected in the brains of 6-OHDA-lesioned rats 4.5 months after administration (20). Similar delivery efficiency of intranasal human neural stem/progenitor cells in an intracerebral model of glioma was reported by Reitz et al. (59). Besides our previously published data on INA of MSCs in the 6-OHDA model of PD, therapeutically efficient intranasal delivery of different types of cells (MSCs, T-regulatory cells, neural stem/progenitor cells) was successfully shown in a variety of disease models [for review, see (12)], such as neonatal ischemia (71), stroke (74), 6-OHDA model of PD (9), neonatal brain damage (23), EAE model $(28,75)$, and intracerebral glioma models $(4,59)$. Thus, INA provides a more efficient and targeted method for delivering cells to the brain than systemic administration. Moreover, INA of therapeutic cells helps to avoid problems associated with surgical transplantation, such as the low survival rate of transplanted cells, limitations in cell dosage, and the impracticality of repeated surgical administration.

Direct intranasal delivery of therapeutic biological molecules to the CNS has been demonstrated by many laboratories over the last two decades involving rapid extracellular delivery along both the olfactory (29) and trigeminal (67) neural pathways [see $(22,49)$ for reviews]. Evidence supporting the involvement of these neural pathways in intranasal delivery of stem cells to the CNS has also been discussed (20,21).

MSCs have been proposed for cell-based therapy of CNS disorders including PD [for review, see Kitada and Dezawa (41)], Alzheimer's (AD) (46), Huntington's disease, stroke, and ALS [for review, see Joyce et al. (37)]. Our previous work showed that INA of bone marrow-derived MSCs in unilaterally 6-OHDA-lesioned rats led to significant improvement of motor deficits reflected by rotational behavior and the stepping test (20). Owing to the potentially higher translational relevance of genetic models of $\mathrm{PD}$, such as the human A30P mutant SNCA (synuclein, $\alpha$ ) gene under the control of a human THY1 (thymus cell antigen $1, \theta$ ) promoter [(Thy1)-h[A30P] $\alpha$ Syn] transgenic mice, in the present study, we investigated whether intranasally applied MSCs can reach the brain regions affected by $\alpha$ Syn $(\alpha \operatorname{Syn})$ pathology in these mice.

Microglia and brain resident macrophages play a significant role in $\mathrm{AD}$ pathology, amyloid beta $(\mathrm{A} \beta$ ) clearance, and in inflammatory processes contributing to the extent of neurodegeneration. Microglia are capable of clearing $\mathrm{A} \beta$ plaques via phagocytosis $(48,62,68)$. This process is enhanced by vaccination against $A \beta(5,42,54)$. Moreover, impaired $\mathrm{A} \beta$ plaque clearance by mononuclear phagocytes has been suggested to be a mechanism for amyloid accumulation in the sporadic form of AD (26).

In view of the increasing number of studies suggesting a protective role of microglia and brain resident macrophages in AD-like pathology, we further assessed intranasal delivery of bone marrow-derived microglia and macrophages to the brain in a transgenic mouse model of $\mathrm{AD}$ and in naive mice.

\section{MATERIALS AND METHODS}

Animals

For isolation of macrophages and MSCs, 12- to 18week-old female $(n=2)$ transgenic C57BL/6-Tg(UBCGFP)30Scha/J mice expressing enhanced green fluorescent 
protein (GFP) under the direction of the human ubiquitin C promoter were purchased from Jackson Laboratory (Bar Harbor, ME, USA).

For INA of macrophages, 13-month-old female chimeric mouse/human amyloid precursor protein $(\mathrm{Mo} /$ HuAPP695swe)/mutant human presenilin 1 (PS1-dE9) [B6. Cg-Tg(APPswe,PSEN1dE9)85Dbo/J] (Stock No. 005864) transgenic mice $(n=3)$ purchased from Jackson Labs were used.

Homozygous (Thy1)-h[A30P] $\alpha \mathrm{S}$ female mice $(n=4)$ were generated as described elsewhere $(39,55)$.

Three-month-old male C57BL/6-GFP mice $(n=10)$ from the Centre for Medical Experiments (MEZ) of the University of Leipzig were used for isolation of bone marrow-derived and culture-differentiated microglia.

Animals were kept under a 12-h dark-to-light cycle, with food and water ad libitum.

All procedures were carried out in accordance with the guidelines for the care and use of laboratory animals of the German Animal Protection Law. The research protocol was approved by the Institutional Board of the Animal Facility of the University Hospital of Tübingen and the local governmental authorities (Regierungspräsidium Tübingen, permit No. PH2/12, and §4 Abs. 3 Az v. 27.02.13), as well as by the Institutional Animal Care and Usage Committee (IACUC) of the Landesdirektion Leipzig (Landesdirektion Sachsen, Leipzig, permit No. TVV 48/12).

\section{Murine eGFP-MSC Isolation and Culture}

Murine MSCs (mMSCs) were isolated from the bone marrow of C57BL/6-Tg(UBC-GFP)30Scha/J male animals at an age of 6 weeks. Bone marrow cells were flushed out of the tibiae and femora under sterile conditions, washed with phosphate-buffered saline (PBS; Lonza, Basel, Switzerland), counted, and seeded at a density of $1 \times 10^{5}$ cells per $\mathrm{cm}^{2}$ in standard culture medium (SCM) composed of minimum essential medium with $\alpha$ modification ( $\alpha$-MEM; Lonza), $1 \%$ penicillin-streptomycin (Lonza), and $10 \%$ pooled fetal calf serum (FCS; Lonza) to tissue culture flasks (Nunc, Roskilde, Denmark). The resulting passage (P) 0 cultures were kept at $37^{\circ} \mathrm{C}$ in humidified atmosphere with 5\% $\mathrm{CO}_{2}$. Reaching subconfluency, MSCs were detached using trypsin-ethylenediaminetetraacetic acid (EDTA; Lonza), counted, and plated to fresh tissue culture flasks for the subsequent passages at a density of 1,000 cells per $\mathrm{cm}^{2}$.

\section{Intranasal Delivery of Cells}

For delivery of MSCs in $\alpha$ Syn mice and macrophages in APP/PS1 mice, intranasal cell or vehicle (PBS) application was performed on awake animals. Prior to vehicle or cell treatment, $\alpha$ Syn and APP/PS1 mice received intranasally $100 \mathrm{U}$ hyaluronidase (Sigma-Aldrich, St. Louis,
MO, USA) dissolved in $24 \mu \mathrm{l}$ sterile PBS to enhance migration of cells to the brain (21). Thirty minutes after intranasal pretreatment with hyaluronidase, cell suspensions $\left(1 \times 10^{6}\right.$ MSCs or $1.5 \times 10^{6}$ macrophages in $40 \mu \mathrm{l}$ of sterile PBS) or vehicle (PBS) were applied in alternating $10-\mu l$ portions for each nostril. Seven days after INA, the animals were sacrificed under ketamine anesthesia (75 mg/kg IP; Ketavet, Pfizer, Germany). The brains were either frozen at $-80^{\circ} \mathrm{C}$ or processed for FACS analyses as described below.

Three-month-old C57BL/6 mice $(n=6)$ received $1 \times$ $10^{6}$ GFP-microglia via INA. After 2 weeks, the animals were anesthetized and sacrificed and the organs isolated for histological or biochemical analysis.

\section{MSC Characterization}

Functional characterization of eGFP-mMSCs involved induction of adipogenic, osteogenic, and chondrogenic differentiation and flow cytometric surface marker analysis. Briefly, adipogenic and osteogenic differentiation of mMSCs was induced at P4 and 41. They were seeded at a density of 1,000 cells per $\mathrm{cm}^{2}$ and kept under standard culture conditions until reaching subconfluency. Subsequently, either adipogenic differentiation was induced using "adipogenic medium" composed of SCM supplemented with $2 \mathrm{nM}$ dexamethasone, $30 \mu \mathrm{M}$ indomethacin, $5 \mu \mathrm{M}$ isobuthylmethylxanthine (IBMX), and $10 \mu \mathrm{g} / \mathrm{ml}$ insulin (all Sigma Aldrich), or osteogenic differentiation was induced using "osteogenic medium" composed of SCM with $10 \mathrm{nM}$ dexamethasone, $0.2 \mathrm{mM}$ ascorbic acid, and $10 \mathrm{mM} \beta$-glycerolphosphate (Sigma Aldrich). After 2 weeks under differentiation conditions, lipid vacuoles in adipogenic cultures were stained with Oil Red O (Sigma Aldrich) and, after 3 weeks, calcium deposits of osteogenic cultures with Alizarin Red S (Sigma Aldrich), respectively. For chondrogenic differentiation, $2.5 \times 10^{5} \mathrm{mMSCs}$ were kept in micromass pellet cultures. Differentiation was induced using the hMSC Chondrogenic Differentiation BulletKit (Lonza), supplemented with transforming growth factor- $\beta 3$ (TGF- $\beta 3$; Lonza). After 4 weeks of differentiation, frozen sections of the fixed pellets were performed and stained with Safranin O (Lonza).

Flow cytometry analysis of mMSCs was performed at P41 using a FACScan instrument (BD Biosciences, Heidelberg, Germany) and BD CellQuest Pro software. Cells were incubated with phycoerythrin (PE)-labeled [anti-cluster of differentiation 4 (CD4), -CD8a, -CD9, -CD11b, -CD11c, -CD14, -CD31, -CD43, -CD44, -CD45, -CD45R/B220, -CD71, -CD73, -CD86, -CD117, -CD135, -CD184, -CD195, -stem cell antigen 1 (SCA-1), -vascular endothelial growth factor receptor 2 (VEGFR2) (all BD Biosciences), and -CD146 (Bio Legend, Fell, Germany)] or unlabeled antibodies [anti-CD29, -CD80, -CD90, -CD105, 
-CD106, -CD140a, -CD144, -mouse major histocompatibility complex class I (H-2K/H2D), -major histocompatibility complex class II (IA/IE) (all BD Biosciences), -CD34 (Abd Serotec, Puchheim, Germany), -CD39 (R\&D, Wiesbaden, Germany), -CD140b (Epitomics, Burlingame, CA, USA), and -CD271 (STEMCELL Technologies, Cologne, Germany)] at a concentration of $0.2 \mu \mathrm{g} / 10^{5}$ cells for $60 \mathrm{~min}$ on ice.

Nonspecific antibody binding was prevented by using the Mouse BD Fc Block ${ }^{\mathrm{TM}}$ (BD Biosciences) at a concentration of $1 \mu \mathrm{g} / 10^{6}$ cells. With regard to the unlabeled primary antibodies, PE-labeled secondary antibodies (mouse anti-rat Ig, donkey anti-goat IgG, goat anti-rat $\mathrm{Ig}$, rat anti-mouse $\operatorname{IgG} 2 \mathrm{a}+\mathrm{b}$ (BD Biosciences), or goat anti-rabbit Ig (Biotrend, Cologne, Germany) were used at a concentration of $0.2 \mu \mathrm{g} / 10^{5}$ cells. Dead cells were excluded by detection of 7-aminoactinomycin D (Sigma Aldrich) uptake. Analysis of percentage of antigen-positive cells was performed using FlowJo software (Tree Star, Inc., Ashland, OR, USA). The respective isotype-matched control was subtracted from all samples to compensate unspecific antibody binding.

\section{Differentiation of Bone Marrow Cells Into Macrophages}

Whole bone marrow cells from femur and tibia of 12to 18-week-old C57BL/6-Tg(UBC-GFP)30Scha/J female $(n=2)$ mice were flushed out, centrifuged, and then cultivated at $3 \times 10^{6}$ cells per $100-\mathrm{mm}$ dish in $10 \mathrm{ml}$ Dulbecco's modified Eagle's medium (DMEM)/10\% FCS/Pen-Strep (all PAA, Linz, Austria) supplemented with macrophagecolony-stimulating factor [M-CSF (R\&D); $30 \mathrm{ng} / \mathrm{ml}$ ]. After 8 and 9 days, cells were washed and detached with cold PBS-EDTA ( $2 \mathrm{mM}$ ) for $30 \mathrm{~min}$ at $4^{\circ} \mathrm{C}$, washed again, and resuspended in PBS $\left(1.5 \times 10^{6}\right.$ cells $\left./ 40 \mu \mathrm{l}\right)$ for the INA.

Flow Cytometry of In Vitro Differentiated Macrophages. An aliquot of detached cells was tested for epidermal growth factor-like module-containing mucin-like hormone receptor-like 1 mouse homolog (F4/80), CD11b, and lymphocyte antigen 6G (Ly6G) expression. The cells were stained with CD11b-phycoerythrin-cyanine 7 (PE-Cy7) (1:400), Ly6G-PE (1:400), and F4/80-Bio (1:100) followed by streptavidin-peridinin-chlorophyll proteincyanine 5.5 (PerCPCy5.5) (1:200; all BD Bioscience) for $20 \mathrm{~min}$ at $4^{\circ} \mathrm{C}$, then cells were washed with PBS, and fluorescence was measured with a FACS-Canto II (BD Bioscience). The purity of differentiated eGFP-positive macrophages was over $90 \%$.

RNA Isolation and Cell Tracking PCR. GFP-positive cells sorted out of the brain hemispheres of animals transplanted with eGFP-macrophages were lysed with RLTBuffer (Qiagen, Hilden, Germany), and for purification and enrichment, the All Prep DNA/RNA Mini Kit (Qiagen) was applied according to the manual. Reverse transcription of
RNA was performed with the Transcriptor High Fidelity cDNA Synthesis Kit (Roche, Mannheim, Germany) according to the protocol provided. The cDNA was analyzed with a nested PCR. Primers for PCR 1 were sense $\left(5^{\prime}\right.$-CTTCAGCCGCTACCCCGACC-3') and antisense (5'-TCGGCGAGCTGCACGCTGCC-3') and generated a product of $330 \mathrm{bp}$. This product was used for the second PCR, yielding a 206-bp product with sense (5'-GTCC AGGAGCGCACCATCTTC-3') and antisense (5'-GATGC CGTTCTTCTGCTTGTCG-3') primers. eGFP-expressing MSCs were used as a positive control, and as a negative control, an astroglial primary culture (APC) was used. The APC was isolated from the whole brains of neonatal C57BL/6 mice (Charles River, Sulzfeld, Germany). The cells were mechanically dissociated, centrifuged, and cultured in DMEM with $4.5 \mathrm{~g} / \mathrm{L}$ glucose (Gibco, Carlsbad, CA, USA) supplemented with $10 \%$ FCS (Biochrom AG, Berlin, Germany), $100 \mu \mathrm{g} / \mathrm{ml}$ streptomycin sulfate, 100 units/ $\mathrm{ml}$ penicillin $\mathrm{G}$, and $100 \mathrm{mM}$ sodium pyruvate (all PAA Laboratories) in a humidified $10 \% \mathrm{CO}_{2}$ atmosphere at $37^{\circ} \mathrm{C}$. After three passages, at day 15 in culture, the cells were frozen until further processing for RNA isolation and PCR. Both PCRs were performed with a LightCycler 480 (Roche) with a primary 5-min denaturation step at $95^{\circ} \mathrm{C}$; 40 cycles with 10 -s denaturation at $95^{\circ} \mathrm{C}, 10$-s annealing at $60^{\circ} \mathrm{C}$, and 10 -s elongation at $72^{\circ} \mathrm{C}$; and a melting curve as a final step with $5 \mathrm{~s}$ at $95^{\circ} \mathrm{C}$ and $1 \mathrm{~min}$ at $65^{\circ} \mathrm{C}$. The PCR products were stored at $4^{\circ} \mathrm{C}$ until analysis on a Qiaxcel (Qiagen).

\section{Fluorescence-Activated Cell Sorting}

Fluorescence-activated cell sorting (FACS) was performed with a BD FACS Aria II flow cytometer (BD Biosciences) using a 100- $\mu$ m nozzle.

Forward-sideward scatter dot plots were used to exclude debris and cell aggregates.

EGFP was excited by a 488-nm laser. Emission filter was 530/30 nm. To avoid false-positive events, the brain suspension of wild-type (WT) mice intranasally treated with vehicle (hyaluronidase in PBS) was employed as a negative control, while the cell suspension of cultured eGFP-MSCs served as a positive control to set the gates for detection of eGFP-positive MSCs after INA.

\section{Differentiation of Bone Marrow Cells Into Microglia}

Whole bone marrow $\left(10^{7}\right.$ cells) was cultivated for 10 days in $10 \mathrm{ml}$ DMEM/10\% FCS in a $60-\mathrm{mm}$ nonadherent Petri dish and differentiation performed as previously described (34).

Genomic DNA ( $g D N A$ ) Isolation. Mice were sacrificed, $1 \mathrm{ml}$ blood was taken, and mice were perfused with $0.9 \%$ $\mathrm{NaCl}$ (Sigma-Aldrich, Munich, Germany). Organs were manually homogenized in peqGOLD TriFast ${ }^{\mathrm{TM}}$ (PeqLab, Erlangen, Germany), and gDNA was isolated according 
to the manufacturer's protocol (PeqLab). Thereafter, gDNA was fragmented by passing it through an injection needle (size 2; B. Braun Melsungen AG, Melsungen, Germany) using a 1-ml syringe (Braun). For purification and enrichment, the gDNA clean-up XS-kit (MachereyNagel, Dueren, Germany) was applied according to the manual.

Cell Tracking qPCR. gDNA of the eGFP-positive transplanted cells was tracked in the recipient mice using an eGFP-specific primer (U55761.1, sense: 5'-CATGGTGA GCAAGGGCGAGGA; antisense: 5'-CTTCAGGGTCAG CTTGCCGTAGG). 36B4 (ribosomal protein, large, P0; Rplp0) was used as a reference (NM_007475.5; sense: 5'-CCGTGTGAGGTCACTGTGCCAGCTC; antisense: 5'-GCCCAAAGCCTGGAAGAAGGAGGTC). Quantitative PCR was done on the DNA Engine Opticon2 (Biorad, Munich, Germany) using Sybr 2x Mastermix (Life Technologies GmbH, Darmstadt, Germany), 1x SybrGreen (Life Technologies $\mathrm{GmbH}$ ), and $0.2 \mu \mathrm{M}$ primer each. Each sample was run in triplicate, and a dilution series for the standard curve was done with plasmid positive controls for absolute quantification. A signal of two molecules 36B4 counted as one diploid cell. The PCR was run with the following cycle conditions: primary denaturation at $95^{\circ} \mathrm{C}$ for $3 \mathrm{~min}, 35$ cycles with $30 \mathrm{~s}$ at $95^{\circ} \mathrm{C}, 30 \mathrm{~s}$ at $60^{\circ} \mathrm{C}$, and $30 \mathrm{~s}$ at $72^{\circ} \mathrm{C}$. Fluorescence measurement was done at $72^{\circ} \mathrm{C}$ for $36 \mathrm{~B} 4$ and $86^{\circ} \mathrm{C}$ for eGFP.

\section{Histologic Analyses}

For histologic analyses of eGFP-MSC or -macrophage treated APP/PS1 or (Thy1)-h[A30P] $\alpha$ Syn mice, sagittal brain sections ( $20 \mu \mathrm{m}$ thick) were fixed in formaldehyde (Otto Fischar GmBH \& Co. KG, Saarbrucken, Germany), washed in PBS, and stained with rabbit polyclonal von Willebrand factor (vWF) antibody diluted 1:300 (DakoCytomation, Glostrup, Denmark) or polyclonal ionized calcium-binding adapter molecule-1 (Iba-1) antibody diluted 1:500 (Wako, Richmond, VA, USA) or monoclonal $\beta$ amyloid antibody diluted 1:1,000 (6E10, Covance, Munich, Germany), or rabbit polyclonal glial fibrillary acidic protein (GFAP) antibody diluted 1:500 (DakoCytomation) for $2 \mathrm{~h}$ at room temperature (RT). Immunofluorescence staining of phosphorylated $\alpha$ Syn was performed using rabbit anti-pS129 (1:500, clone EP1536Y, Epitomics, Burlingame, CA, USA) and incubated overnight. Secondary goat anti-rabbit antibody cyanine 3 (Cy3) diluted 1:800 (Dianova, Jackson Immunoresearch, West Grove, PA, USA) and Vectashield mounting medium containing 4',6-diamidino-2-phenylindole (DAPI; Linaris, Wertheim-Bettingen, Germany) were used for visualization of antigens and the cell nuclei. Three-dimensional imaging of the blood vessels stained with vWF was performed using a $z$-stack of 17 optical sections, $17 \mu \mathrm{m}$ in total thickness using an Olympus IX-81 microscope and the CellP software (Olympus Soft Imaging Solutions $\mathrm{GmbH}$, Leinfelden-Echterdingen, Germany).

For analyses of brain sections obtained from animals treated with eGFP-microglia, C57C57/BL6 mice were sacrificed and perfused with $4 \%$ paraformaldehyde (PFA; Sigma-Aldrich, Munich, Germany). Fixed brains were incubated at $4{ }^{\circ} \mathrm{C}$ for $24 \mathrm{~h}$ in $4 \%$ PFA followed by incubation in $30 \%$ sucrose (Sigma-Aldrich, Munich, Germany). Frozen tissue embedded in Tissue Tek (Sakura, Staufen, Germany) was cut into $40-\mu \mathrm{m}$ sections. The whole brain sections were evaluated for accumulation of eGFP-positive cells. Immunohistological staining of brain sections with Iba-1 antibody (1:700; Wako) was performed. Secondary antibody Cy3-conjugated donkey anti-rabbit antibody (1:1,000; Dianova) was used.

\section{Statistical Analyses}

Analyses of FACS and qPCR data were performed by one-way ANOVA with Bonferroni's test for multiple comparisons; $p<0.05$ was considered significant. The data are presented as mean \pm SEM.

\section{RESULTS}

Adipo-/Osteo-/Chondrogenic Lineage Differentiation Potency of Murine eGFP-MSCs and Surface Marker Profile of eGFP-MSCs and eGFP-Macrophages

Prior to INA, surface markers of bone marrow-derived eGFP-MSCs were characterized by FACS. Figure 1 shows that in vitro, prior to INA, eGFP-MSCs were positive for CD9, CD43, CD44, CD71, CD29, CD39, CD105, CD106, SCA-1, CD80, CD146, and H2K-H2D and negative for CD45, CD14, CD11c, CD11b, CD4, CD8a, CD31, CD34, CD45R-B220, CD86, CD73, CD90, CD117, CD135, CD73, CD140a and b, CD144, CD184, CD195, CD271, I-A/I-E, and VEGF-R2 (data not shown). In vitro differentiation experiments of eGFP-MSCs (Fig. 2) demonstrated the ability of eGFP-MSCs to differentiate into adipogenic(Fig. 2B), osteogenic- (Fig. 2D), and chondrogenic-like (Fig. 2F) cells.

In vitro differentiation of murine eGFP macrophages yielded a purity of over $90 \%$ as depicted in Figure 2A, showing eGFP macrophages stained for F4/80 and CD11b.

\section{INA Delivery of eGFP-Microglia to the Brains and Inner Organs of BL/6 Mice}

Analysis of biodistribution by PCR showed that in the brain, the highest number of cells was found in the OB, while hippocampus, cortex, and cerebellum contained nearly the same amount of cells; no cells were found in the brainstem (Fig. 3A). Among peripheral organs and tissues, most of the cells were found in the blood, lungs, and thymus; however, the mean of the cells in all analyzed peripheral organs did not exceed $3.4 \times 10^{3}$ cells per organ/tissue type, while the maximal number of cells in the brain was 

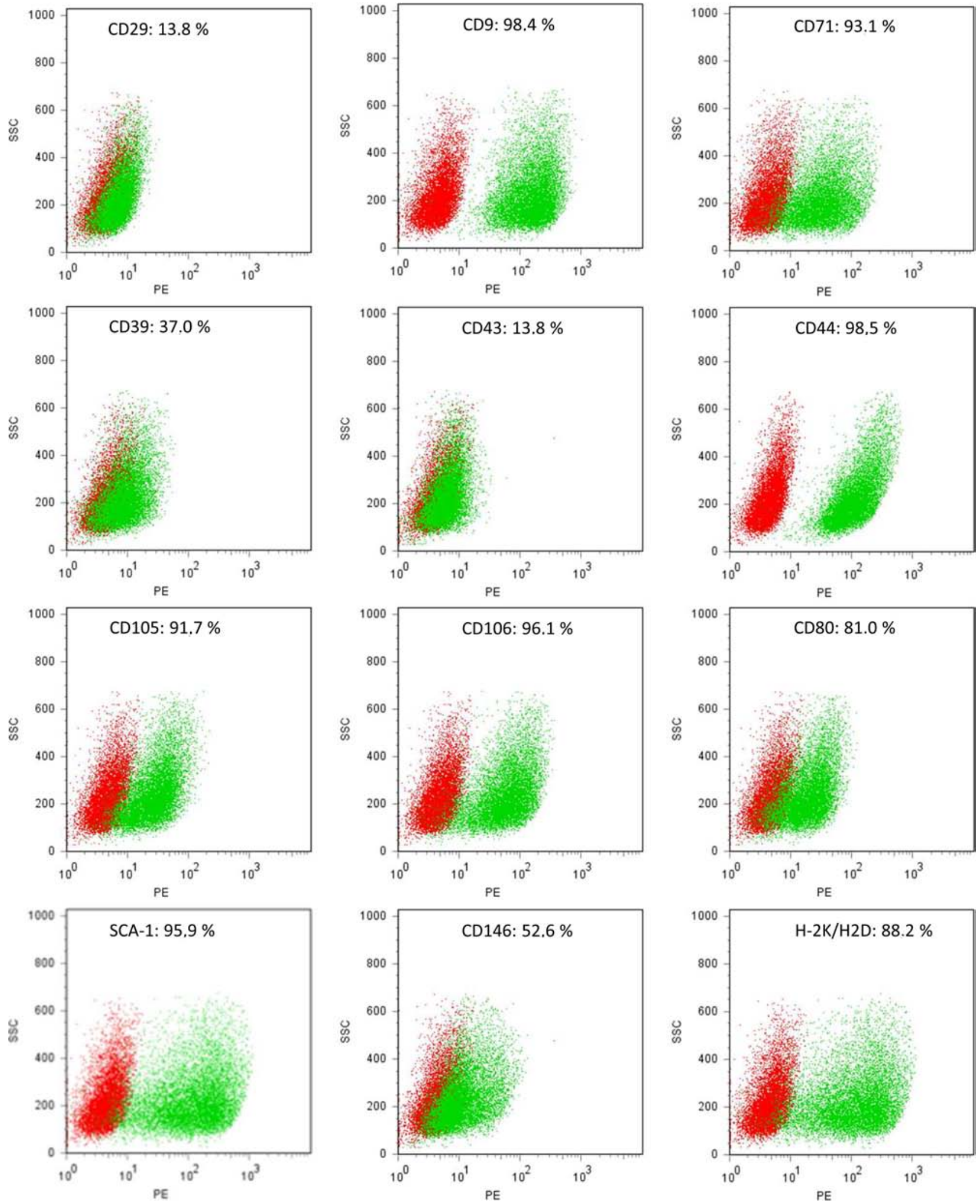

Figure 1. FACS analyses of eGFP-MSC surface markers prior to INA. Dot plots show the specific antibody (green) and the respective isotype control (red) profiles. FACS, fluorescent-activated cell sorting; eGFP, enhanced green fluorescent protein; MSC, mesenchymal stem cell; INA, intranasal application; CD29, cluster of differentiation 29; PE, phycoerythrin; SSC, side scatter; SCA-1, stem cell antigen $1 ; \mathrm{H}-2 \mathrm{~K} / \mathrm{H} 2 \mathrm{D}$, mouse major histocompatibility complex class I. 
$2.1 \times 10^{4}$. Comparison of the amount of eGFP-microglia detected in the brain to those from peripheral organs/tissues revealed significantly higher numbers of cells when compared with thymus, bone marrow, submandibulary lymph nodes, liver, kidney, spleen, and heart samples (Fig. 3B). The comparison of brain versus blood or lung samples revealed a slight, however not significant, difference.

Analysis of brain sections showed that the majority of the intranasally transplanted eGFP-microglia were found in the corpus callosum, hippocampus, and striatum (Fig. 4A-D) To determine whether transplanted cells retain their functional activity, Iba- 1 staining was performed, and some cells were found to be positive (arrows throughout Fig. 4). Most of the eGFP-microglia showed a rounded, ameboid morphology.

\section{Distribution of eGFP-MSCs in the Brains of PD Transgenic Mice After INA}

The EGFP-MSCs were detected in various brain regions of aged (Thy1)-h[A30P] $\alpha$ Syn transgenic mice 7 days after INA. The most prominent migration was seen toward the OB and brainstem (Fig. 5A-D). MSCs appeared in close proximity to phosphorylated $\alpha$ Syn aggregates (Fig. 5A, C), and astrogliosis was reflected by a strong reactivity of glial fibrillary acidic protein (GFAP) (Fig. 5B, D). Numerous eGFP-MSCs were closely associated with vessels stained with vWF (Fig. 5E), showing, however, the parenchymal localization.

We further quantified the distribution of intranasally delivered eGFP-MSCs in brain regions of one hemisphere per animal $(n=4)$ and isolated these cells by FACS for further analysis of eGFP cDNA to confirm their viable stage at the point of the brain preparation. Quantitative analysis of eGFP-MSC distribution in the brains of (Thy1)-h[A30P] $\alpha$ Syn transgenic mice 7 days after INA demonstrated that MSCs were present in all investigated brain areas. A slightly, however insignificantly, higher number of eGFP-MSCs were observed in the brainstem and OB (Fig. 6A) in comparison with other brain regions (hippocampus, cerebellum, amygdala, and remaining brain). The total number of eGFP-MSCs detected per brain hemisphere was $834 \pm 242(n=4)$. Samples of eGFPMSCs isolated from the different brain areas of the cerebral hemispheres by FACS were pooled for the analysis of eGFP cDNA. Figure 6B shows the presence of eGFP cDNA in the brains of (Thy1)-h[A30P] $\alpha$ Syn transgenic mice treated intranasally with eGFP-MSCs. Astroglial primary culture of postnatal C57BL/6 mice served as a negative control, while cultured eGFP-MSCs served as a positive control.

Figure 6C-E shows gating for detection of eGFPMSCs (eGFP events in the OB and brainstem are shown in Fig. $6 \mathrm{C}$ and D, and the negative WT control is shown in Fig. 6E).
Delivery of eGFP-Macrophages to

the Brains of APP/PS1 Mice

Intranasal delivery of bone marrow-derived and culture-differentiated macrophages to the brain was also evaluated using a transgenic mouse model of AD. Seven days after INA of cells, the brains were analyzed by fluorescence microscopy for the presence of eGFPmacrophages (Fig. 7).

EGFP-macrophages appeared in the hippocampus and occipital cortex closely associated with $A \beta$ plaques (arrows in Fig. 7A, B). Numerous eGFP-macrophages were positive for $\mathrm{A} \beta$ (arrows in Fig. 7A, B, and F), while others located beside the $A \beta$ plaques did not reveal $A \beta$ positivity (arrowheads in Fig. 7A).

Two major populations of eGFP-macrophages were identified in the brains of APP/PS1 transgenic mice: 1) Iba-1-positive eGFP-macrophages (arrows in Fig. 7E) showing a very similar morphology to Iba-1-positive host microglial cells and 2) Iba-1-negative eGFP-macrophages with either rounded large cell bodies (arrowheads in Fig. 7A, E) or spindle-like shape (arrowhead in Fig. 7C).

Interestingly, numerous Iba-1-negative eGFP-macrophages were seen in the inferior cerebellar peduncle (ICP, Fig. 7D) and cerebellum (Fig. 7F) closely associated with $\mathrm{A} \beta$-positive host tissue. The presence of $\mathrm{A} \beta$ plaques in the cerebellum was recently shown in APP/PS1 transgenic mice (50).

\section{DISCUSSION}

The present study shows, for the first time, intranasal delivery of bone marrow-derived MSCs, macrophages, and microglia to the brain in transgenic mouse models of $\mathrm{PD}$ and $\mathrm{AD}$, respectively.

The rationale for using MSCs as potential candidates in cell therapy for PD is based on a variety of studies showing and/or suggesting the advantages of MSCs following IV or intracerebral administration in vivo [for review, see Kitada and Dezawa (41)].

MSCs are known to possess strong immunomodulatory [for review, see Yagi et al. (77)], anti-inflammatory, and neuroprotective capacities in a variety of neurodegenerative disease models including $\mathrm{AD}, \mathrm{PD}$, multiple sclerosis, ALS, and traumatic brain injury $(10,37,40,46,72)$. While our previous report on intranasal MSCs and numerous others using IV versus intracerebral transplantation proved the therapeutic efficacy of these cells in the 6-OHDA-induced PD model (41), none of the studies in the past investigated the delivery and therapeutic potency of intranasally delivered or surgically transplanted MSCs in genetic models of PD. To our knowledge, only the single report of Stemberger et al. (66) showed therapeutic potency of intravenously applied MSCs in a mouse model of multiple system atrophy (MSA). The hallmarks of this model [proteolipid protein promotor (PLP)- $\alpha$ Syn transgenic mice], namely, 

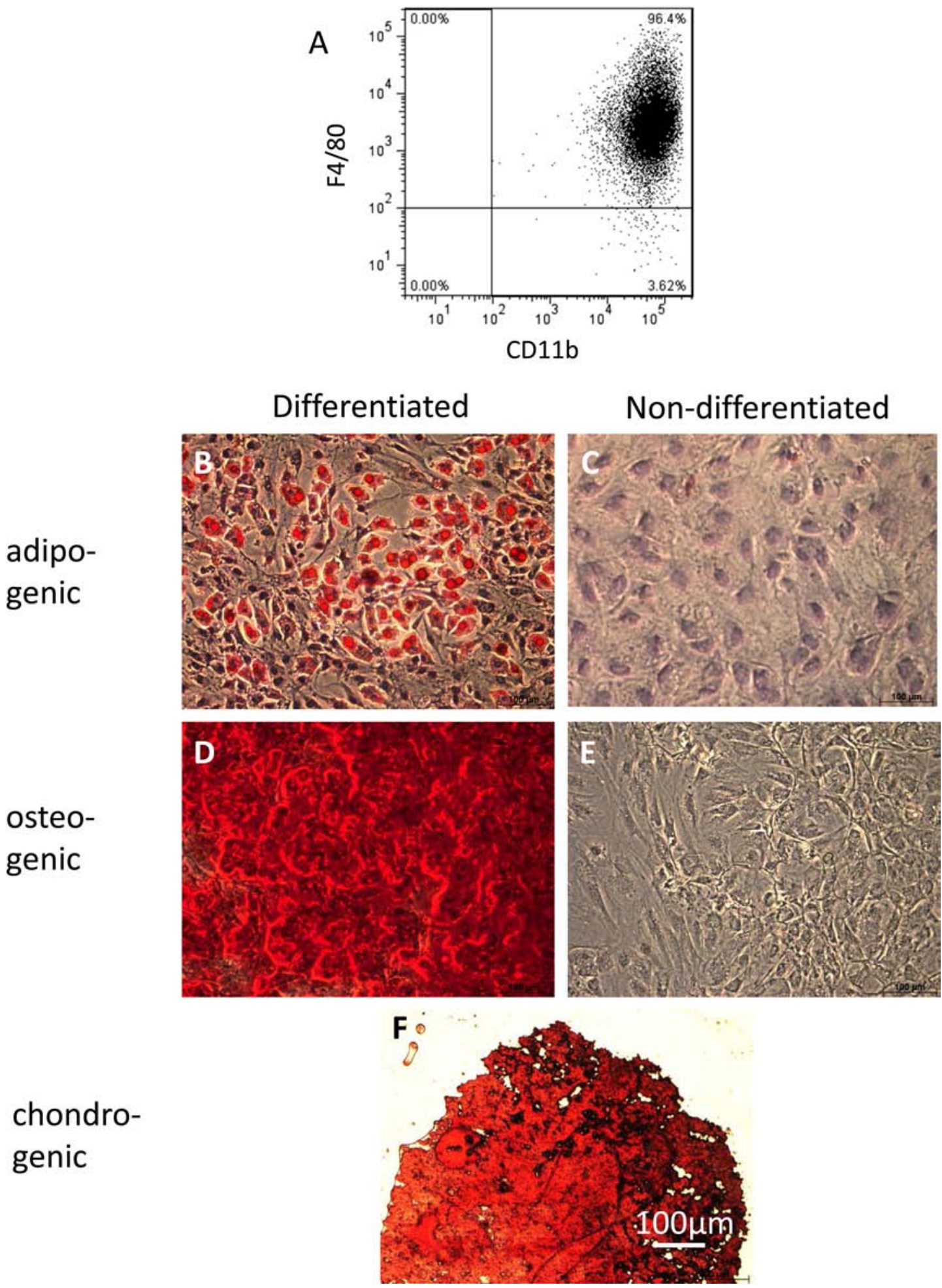

Figure 2. Expression of macrophage-lineage specific markers and trilineage differentiation potential of MSCs. (A) After 9 days of differentiation of bone marrow cells, purity of generated macrophages was determined by staining with CD11b and F4/80. In all experiments, purity over $90 \%$ was achieved. One representative plot is shown. (B-F) MSCs treated with the respective culture media show adipogenic, osteogenic, and chondrogenic lineage differentiation in vitro. (B) Adipocyte-like phenotype of MSCs shown by the presence of lipid vacuoles stained in red with Red Oil O. (C) Undifferentiated MSCs as control to (B). (D) Alizarin Red-stained calcium deposits in osteogenic differentiated MSCs. (E) Undifferentiated MSCs as control to (D). (F) Chondrogenic differentiated MSCs show pellets of mucopolysaccharides stained in red with Safranin O. Scale bar: $100 \mu \mathrm{m}$. 


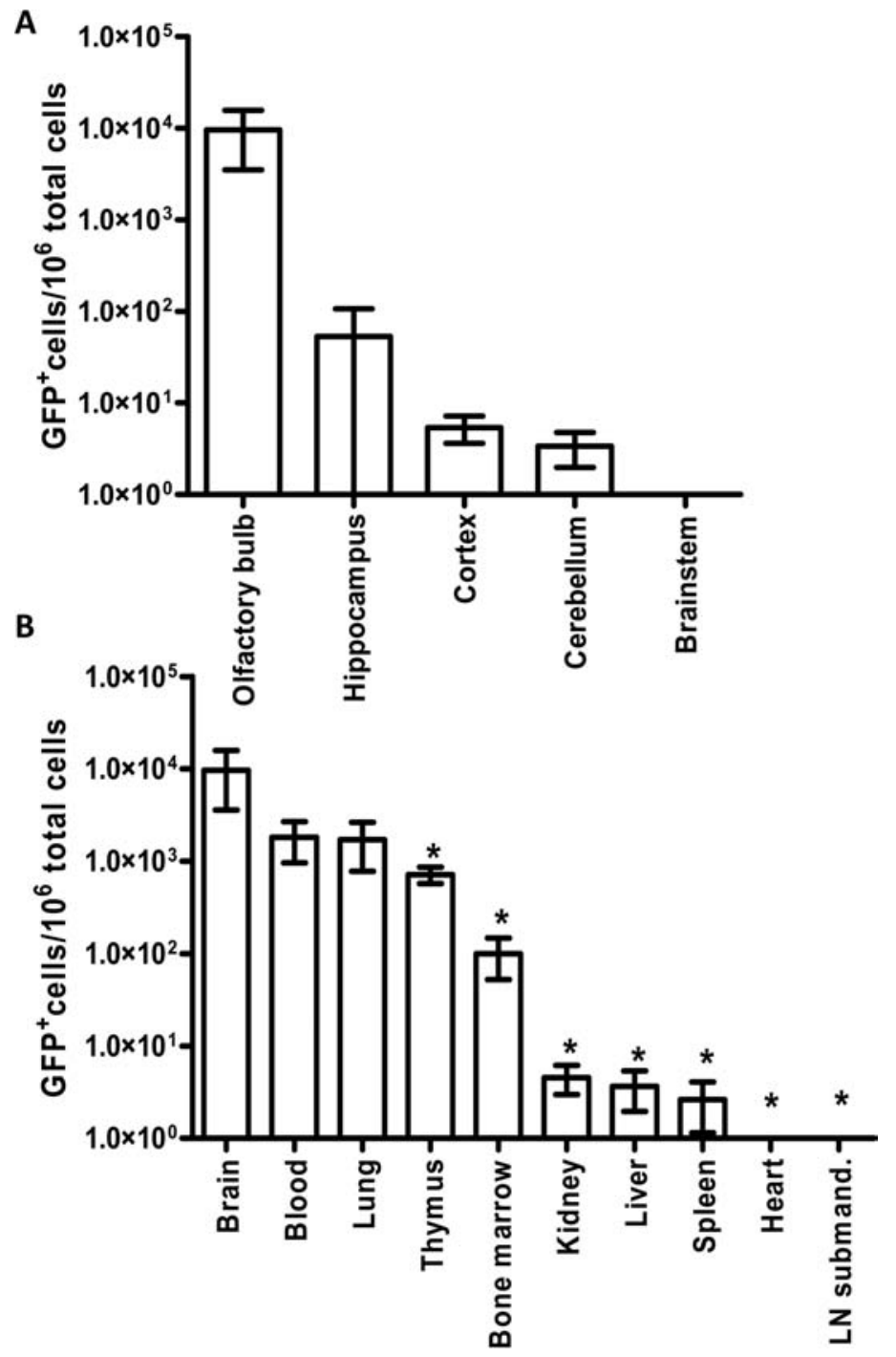

Figure 3. Distribution of $1 \times 10^{6} \mathrm{INA}$ microglia in the brains and peripheral organs/tissues of 3-month-old C57BL/6 mice. eGFP-positive microglia were analyzed by qPCR of GFP genomic DNA. As a reference, the single copy gene 36B4 was used. Two copies were counted as one diploid cell. The cell number is shown as GFP-positive cells per $1 \times 10^{6}$ total host cells. Distribution of transplanted cells is shown in the brain (A) and in the peripheral organs and tissues (B). In the brain, the numbers of cells in hippocampus, cortex, cerebellum, and brainstem were compared with those from the OB. In addition, the total brain number of eGFP-positive cells was compared to those detected in peripheral organs/tissues (B). ${ }^{*} p<0.05$.

glial cytoplasmic inclusions of $\alpha$ Syn, astrogliosis, and microglial activation, provide the link of the MSA model to PD and dementia with Lewy bodies pathologies (64). IV application of $5 \times 10^{5}$ MSCs in a mouse MSA model led to a downregulation of neuroinflammatory cytokines and rescued tyrosine hydroxylase (TH)-positive neurons in the substantia nigra pars compacta (66) 4 weeks after MSC treatment. However, neither behavioral improvement nor changes in $\alpha$ Syn concentration in midbrainbrainstem lysates were achieved by IV MSC administration. Regrettably, this study did not include the quantification of MSCs delivered to the CNS after IV application. A report by Camp et al. (11) showed that the survival of MSCs after intrastriatal transplantation in unilateral 6-OHDA was as low as approximately 8,000 cells out of $4 \times 10^{5}$ MSCs applied. The study by Wang et al. demonstrated no survival of MSCs in the brain at the endpoint (4 weeks posttransplantation), while very few cells (no exact number available) were detected in 6-OHDA-lesioned brain 1 week after IV delivery of $1 \times 10^{7} \mathrm{MSCs}$ (73). Our data show that at least $2,078 \pm 364$ cells can be delivered to the brain of (Thy1)-h[A30P] $\alpha$ Syn transgenic mice by a single INA, suggesting far better efficacy than that achieved with IV administration. Moreover, it is likely that repeated INA of 

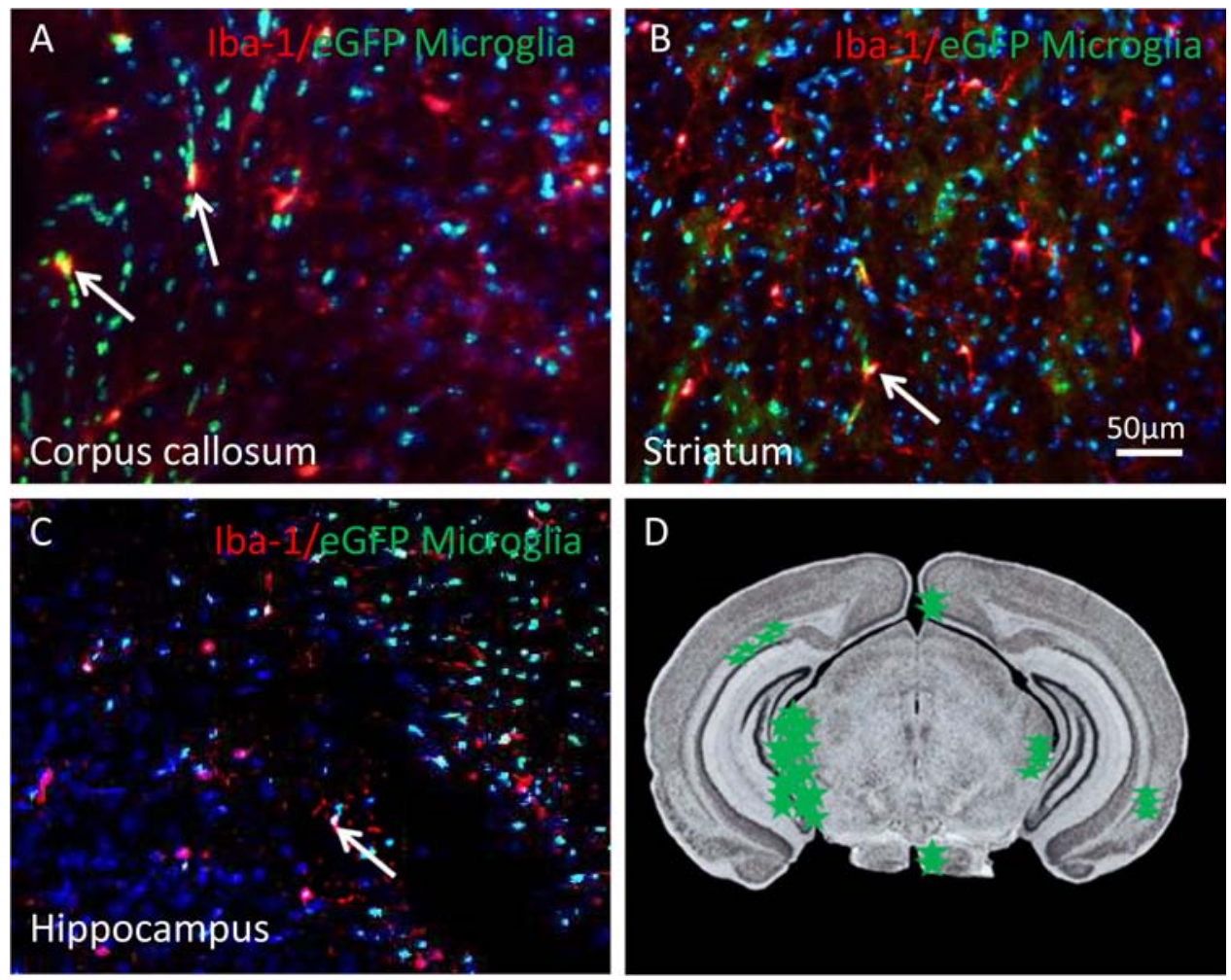

Figure 4. Detection of eGFP-positive microglia in the brains of 3-month-old C57BL/6 mice 2 weeks after INA. Sections stained with ionized calcium-binding adapter molecule 1 (Iba-1; red) and 4',6-diamidino-2-phenylindole (DAPI) nuclear staining (blue) show the presence of eGFP-positive microglia (green) in corpus callosum (A), striatum (B), and hippocampus (C). The majority of cells showed negative immunoreactivity to Iba-1 [green cells in (A-C)], while a small population of eGFP-microglia was Iba-1 positive (arrows in A-C). (D) Schematic location of eGFP-positive microglia found in the brain slides after INA. Scale bar: $50 \mu \mathrm{m}$.

MSCs may achieve and even exceed the number of cells that are delivered and survive after surgical transplantation, which are extremely limited and may not justify its use. Present data showing that a certain population of administered MSCs, detected in the brainstem, contain phosphorylated $\alpha$ Syn hint at their possible ability to participate in the clearance of $\alpha$ Syn from the extracellular space, thus reducing endocytotic uptake of $\alpha$ Syn by host glia and consequently attenuating glial inflammatory response $(7,45)$.

Microglia and blood-circulating monocytes are considered to play a prominent role in neuroinflammatory response and disease exacerbation in $\mathrm{AD}$. Whether and how they affect the formation and clearance of $A \beta$ plaques is controversial. While depleting perivascular macrophages (33) and inhibiting their recruitment to the CNS is associated with accumulation and reduced clearance of $A \beta(25)$, the depletion of brain microglia was reported not to affect $\mathrm{A} \beta$ plaque load in two distinct APP transgenic mouse models (31).

Our present data show for the first time the successful delivery of cells to the brain in a model of AD via INA. In particular, bone marrow-derived macrophages were detected in different brain areas affected by $\mathrm{A} \beta$ plaque pathology 7 days after INA in APP/PS1 mice. While the $A \beta$ positivity of eGFP-macrophages may reflect its internalization, the contribution of allogenic macrophages from healthy animals to the overall brain clearance of $\mathrm{A} \beta$ in a transgenic mouse model of $\mathrm{AD}$ needs to be further explored. The phagocytic activity of monocytes/ macrophages was recently shown to be impaired in $\mathrm{AD}$ patients $(3,26,60,79)$. Thus, future development of in vitro methods to enhance the phagocytic activity of patients' own monocytes may offer a new strategy of administering reprogrammed monocytes/macrophages to improve $A \beta$ clearance in AD patients. Since INA allows chronic noninvasive application of cells, this delivery method could be used to mimic boosting of monocyte production and their recruitment to the CNS, without wasteful systemic distribution of in vitro engineered cells (when compared with systemic application) or acute inflammatory response of the host tissue after surgical transplantation.

We analyzed the success and the distribution of intranasally applied microglia in a naive mouse to explore whether more targeted migration of cells to the brain can be achieved in naive animals lacking inflammatory processes in the brain that could facilitate cell guidance. Our 

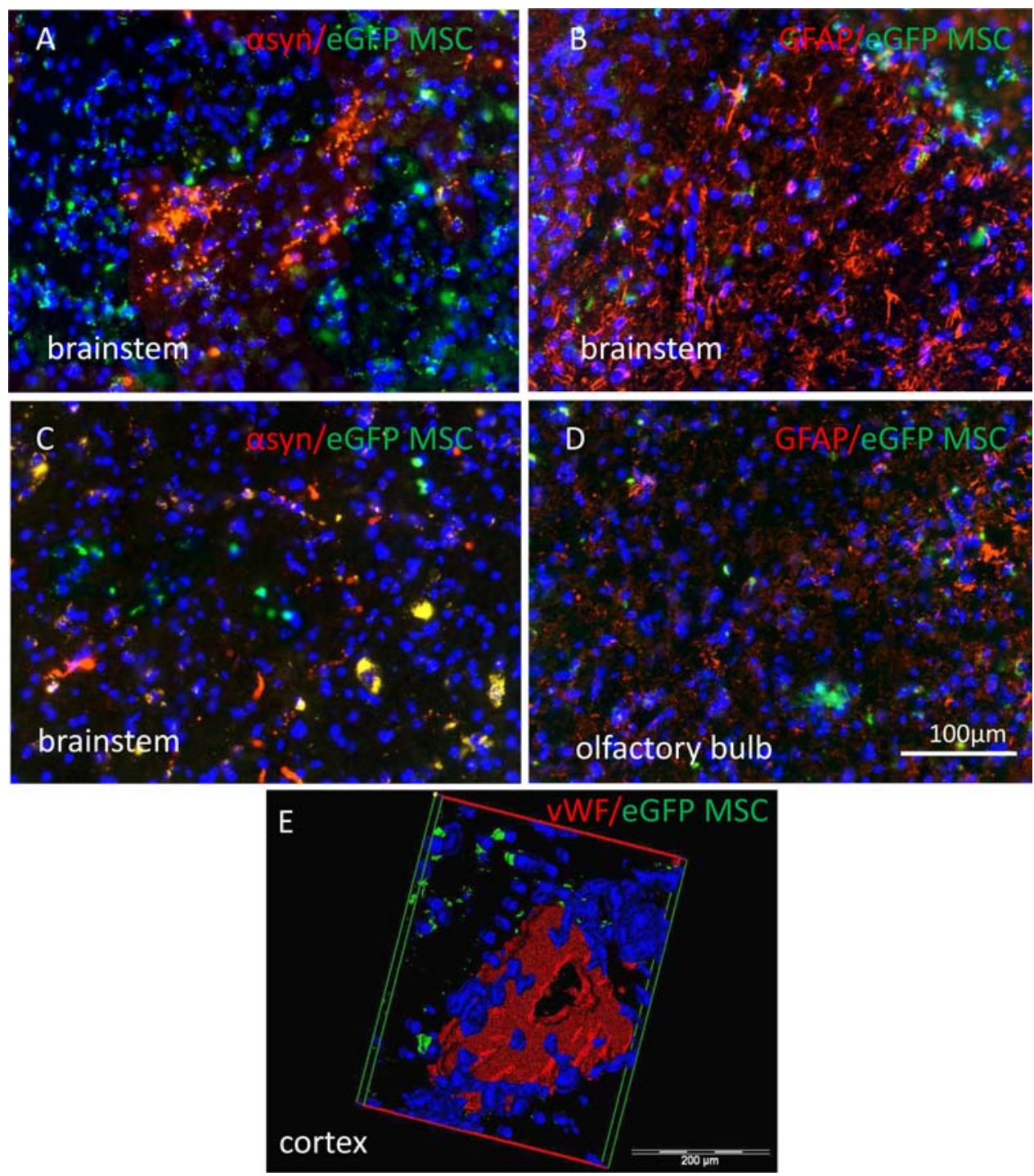

Figure 5. Detection of eGFP-MSCs in the brains of 18-month-old $\alpha$ Syn transgenic mice 7 days after INA. Brain sections stained with antibodies against either phosphorylated $\alpha$-synuclein $(\alpha \operatorname{Syn})$ (red in A, C, and E) or glial fibrillary acidic protein (GFAP) (red in B and D) contain eGFP-positive MSCs (green and/or yellowish in A-E) located in the close vicinity of $\alpha$ Syn aggregates in the brainstem (A, E) or reactive astroglia strongly expressing GFAP in the olfactory bulb (D). MSCs were found in the close proximity of the vessels stained with von Willebrand factor (vWF) in different areas of the brain including cortex (red in E). Scale bar:100 $\mu \mathrm{m}(\mathrm{A}-\mathrm{D}), 200 \mu \mathrm{m}(\mathrm{E})$.

data show a higher number of cells in the brain of naive mice treated intranasally with microglia in comparison to the peripheral organs and tissues. Among peripheral tissues/organs, the highest number of eGFP-microglia was detected in the blood, suggesting a possible uptake of cells directly from the highly vascularized nasal mucosa $(13,16,35)$ into the bloodstream. However, the amount of cells observed in the blood was as low as $2,475 \pm 646$ ( $0.24 \%$ of applied cells).

Another rationale for therapeutic use of autologous macrophages/monocytes in AD and various other CNS disorders is based on the hypothesis that these cells can serve as genetically modified biologic factories for producing and delivering growth factors that can improve brain cell survival, cognitive function, and $A \beta$ clearance in AD. One candidate that could be delivered by cells is nerve growth factor (NGF) that was shown to impact the survival of cholinergic neurons in lesioned rodents and aged nonhuman primates $(8,69)$. NGF gene therapy was further reported to slow down cognitive decline in the first phase I clinical trial without apparent long-term adverse effects (70). Among other factors capable of multifaceted action in the CNS, erythropoietin (EPO) is a promising candidate. Numerous in vivo and in vitro studies have demonstrated its neuroprotective and neurogenesis-enhancing features in a variety of brain disease models such as 

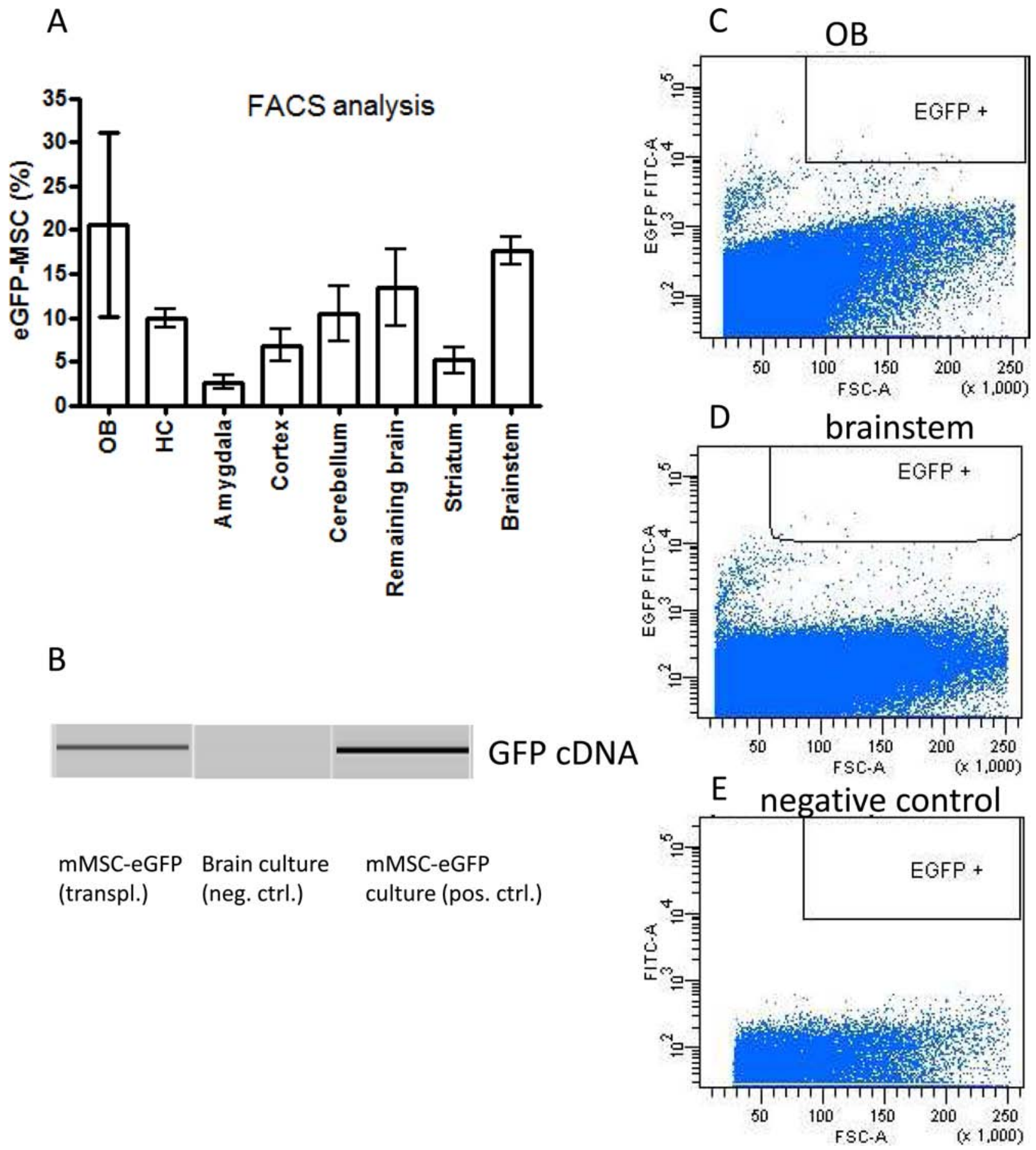

$\begin{array}{lll}\text { mMSC-eGFP } & \text { Brain culture } & \text { mMSC-eGFP } \\ \text { (transpl.) } & \text { (neg. ctrl.) } & \text { culture (pos. ctrl.) }\end{array}$

\section{GFP cDNA}

Figure 6. Distribution of eGFP-MSCs in the brains of 18-month-old $\alpha$ Syn transgenic mice 7 days after INA. The distribution of eGFP-MSCs was determined in dissected and suspended brain areas by FACS analysis. (A) eGFP-positive MSCs were sorted [mMSCeGFP (transpl.)] and further analyzed for the presence of eGFP cDNA. (B) eGFP cDNA obtained from cultured mMSC-eGFP served as a positive control, while brain astroglia-rich primary culture of C57BL/6 neonatal mice served as a negative control [brain culture (neg. ctrl.)]. Exemplary dot plots show eGFP-positive MSCs in the OB (C) and brainstem (D) of $\alpha$ Syn transgenic mice. Negative control settings using the whole brain cell suspension from the wild-type control mouse treated with the vehicle (PBS) are also shown (E). 

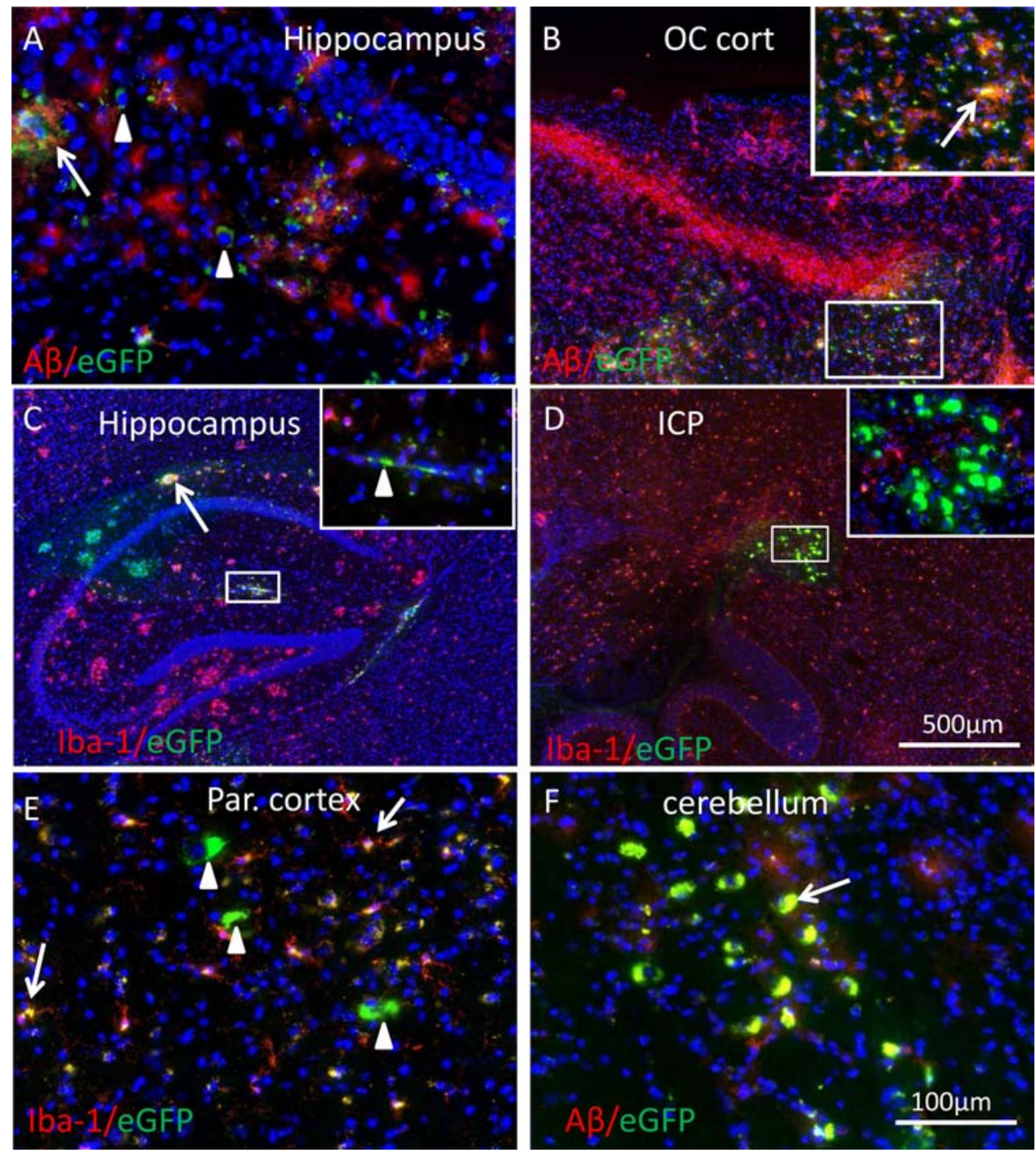

Figure 7. Detection of eGFP-positive murine macrophages in the brains of 13-month-old APP/PS1 mice. Intranasally applied macrophages (green or yellowish cells in A-F) were found in the hippocampus, occipital (OC), and parietal (Par.) cortex, inferior cerebellar peduncle (ICP), as well as in the cerebellum (F). Staining of the sections with antibodies against amyloid $\beta$ (A $\beta$ ) (red in A, B, and D) and Iba-1 (red in C, D, and E) showed the presence of A $\beta$-positive (arrows in A, B, and F) and negative (arrowheads in A), as well as Iba-1-positive (arrows in $\mathrm{C}$ and $\mathrm{E}$ ) and negative (arrowheads in $\mathrm{C}$ and $\mathrm{E}$ ) macrophages. $\mathrm{A} \beta$-positive macrophages were detected in the vicinity of $A \beta$ plaques in the hippocampus (A), cortex (B), and cerebellum (F). Scale bar: $100 \mu \mathrm{m}(\mathrm{A}, \mathrm{E}$, and F), $500 \mu \mathrm{m}(\mathrm{B}, \mathrm{C}$, and D). APP/PS1 mice, amyloid precursor protein/presenilin transgenic mice.

hypoxia and stroke $(17,18,30,36)$, nontransgenic rodent models of AD (1,52), and 6-OHDA model of PD $(38,76)$. EPO improves cognition in patients with neuropsychiatric diseases (24) and spatial learning in mice with transgenic expression of a constitutively active EPO receptor (EPOR) isoform in pyramidal neurons of cortex and hippocampus (61). The improvement of $A \beta$ uptake by MSCs in vitro (19) and decrease in $\mathrm{A} \beta$ plaque burden in $\mathrm{Tg} 2576$ mice (47) are concomitant with results showing the decrease in EPO and upregulation of its receptor during aging in APP/PS1 transgenic mice (51) and increased EPOR in hippocampal and cortical astrocytes in patients with mild cognitive impairment and sporadic AD (2).

Demonstration of intranasal delivery of MSCs and macrophages to the brain in $\mathrm{AD}$ and $\mathrm{PD}$ transgenic mouse models as well as intranasal delivery of microglia to the brains of naive mice provide a basis for further investigations of therapeutic efficacy and a noninvasive intranasal method of treatment for AD and PD.

The advantages of intranasal administration of cells in comparison with systemic or surgical transplantations can be ascribed to 1) its noninvasiveness in comparison with 
surgical transplantation and, thus, the possibility to use multiple applications while avoiding extensive immunological response associated with surgical transplantation and 2) its more targeted and efficacious delivery to the brain in comparison with IV and IA administration.

ACKNOWLEDGMENTS: We wish to thank Cornelia Grimmel (FACS core facility of the interdisciplinary center for clinical research of the University Hospital of Tübingen) and Claudia Müller for excellent technical assistance and advice on data analyses. This work was supported by Applied Clinical Research Program (AKF No. 295-0-0) and the Interfaculty Centre for Pharmacogenomics and Pharma Research (ICEPHA) grant from the Faculty of Medicine, University of Tübingen. W.H.F., L.D., and C.H.F. own the patent on intranasal delivery of cells to the brain (Methods, pharmaceutical compositions, and articles of manufacture for administering therapeutic cells to the animal central nervous system. March 2009: WO/2009/035901). Authors declare no other conflict of interest for this work.

\section{REFERENCES}

1. Arabpoor, Z.; Hamidi, G.; Rashidi, B.; Shabrang, M.; Alaei, H.; Sharifi, M. R.; Salami, M.; Dolatabadi, H. R.; Reisi, P. Erythropoietin improves neuronal proliferation in dentate gyrus of hippocampal formation in an animal model of Alzheimer's disease. Adv. Biomed. Res. 1:50; 2012.

2. Assaraf, M. I.; Diaz, Z.; Liberman, A.; Miller, Jr., W. H.; Arvanitakis, Z.; Li, Y.; Bennett, D. A. Brain erythropoietin receptor expression in Alzheimer disease and mild cognitive impairment. J. Neuropathol. Exp. Neurol. 66:389-398; 2007.

3. Avagyan, H.; Goldenson, B.; Tse, E.; Masoumi, A.; Porter, V.; Wiedau-Pazos, M.; Sayre, J.; Ong, R.; Mahanian, M.; Koo, P.; Bae, S.; Micic, M.; Liu, P. T.; Rosenthal, M. J.; Fiala, M. Immune blood biomarkers of Alzheimer disease patients. J. Neuroimmunol. 210:67-72; 2009.

4. Balyasnikova, I. V.; Prasol, M. S.; Ferguson, S. D.; Han, Y.; Ahmed, A. U.; Gutova, M.; Tobias, A. L.; Mustafi, D.; Rincón, E.; Zhang, L.; Aboody, K. S.; Lesniak, M. S. Intranasal delivery of mesenchymal stem cells significantly extends survival of irradiated mice with experimental brain tumors. Mol. Ther. 22:140-148; 2014.

5. Bard, F.; Cannon, C.; Barbour, R.; Burke, R. L.; Games, D.; Grajeda, H. Peripherally administered antibodies against amyloid beta-peptide enter the central nervous system and reduce pathology in a mouse model of Alzheimer disease. Nat. Med. 6:916-919; 2000.

6. Barker, R. A.; Dunnett, S. B.; Faissner, A.; Fawcett, J. W. The time course of loss of dopaminergic neurons and the gliotic reaction surrounding grafts of embryonic mesencephalon to the striatum. Exp. Neurol. 141:79-93; 1996.

7. Béraud, D.; Hathaway, H. A.; Trecki, J.; Chasovskikh, S.; Johnson, D. A.; Johnson, J. A.; Federoff, H. J.; Shimoji, M.; Mhyre, T. R.; Maguire-Zeiss K. A. Microglial activation and antioxidant responses induced by the Parkinson's disease protein $\alpha$-synuclein. J. Neuroimmune Pharmacol. 8:94-117; 2013.

8. Blesch, A.; Tuszynski, M. Ex vivo gene therapy for Alzheimer's disease and spinal cord injury. Clin. Neurosci. 3:268-274; 1995.

9. Bossolasco, P.; Cova, L.; Levandis, G.; Diana, V.; Cerri, S.; Lambertenghi Deliliers, G.; Polli, E.; Silani, V.; Blandini, F.; Armentero, M. T. Noninvasive near-infrared live imaging of human adult mesenchymal stem cells transplanted in a rodent model of Parkinson's disease. Int. J. Nanomedicine 7:435-447; 2012.

10. Calvo, A.; Moglia, C.; Balma, M.; Chiò, A. Involvement of immune response in the pathogenesis of amyotrophic lateral sclerosis: A therapeutic opportunity? CNS Neurol. Disord. Drug Targets 9:325-330; 2010.

11. Camp, D. M.; Loeffler, D. A.; Farrah, D. M.; Borneman, J. N.; LeWitt, P. A. Cellular immune response to intrastriatally implanted allogeneic bone marrow stromal cells in a rat model of Parkinson's disease. J. Neuroinflammation $6: 17 ; 2009$.

12. Chapman, C. D.; Frey, 2nd, W. H.; Craft, S.; Danielyan, L.; Hallschmid, M.; Schiöth, H. B.; Benedict, C. Intranasal treatment of central nervous system dysfunction in humans. Pharm. Res. 30:2475-2484; 2013.

13. Chien, Y. W.; Su, K. S. E.; Chang, S. F. Anatomy and physiology of the nose. In: Chien, Y. W.; Su, K. S. E.; Chang, S. F., eds. Nasal systemic drug delivery. New York, NY: Marcel Dekker; 1989:1-26.

14. Coyne, T. M.; Marcus, A. J.; Reynolds, K.; Black, I. B.; Woodbury, D. Disparate host response and donor survival after the transplantation of mesenchymal or neuroectodermal cells to the intact rodent brain. Transplantation 84: 1507-1516; 2007.

15. Coyne, T. M.; Marcus, A. J.; Woodbury, D.; Black, I. B. Marrow stromal cells transplanted to the adult brain are rejected by an inflammatory response and transfer donor labels to host neurons and glia. Stem Cells 24:2483-2492; 2006.

16. Dale, O.; Hjortkjaer, R.; Kharasch, E. D. Nasal administration of opioids for pain management in adults. Acta Anaesthesiol. Scand. 46:759-770; 2002.

17. Danielyan, L.; Gembizki, O.; Proksch, B.; Weinmann, M.; Morgalla, M.; Wiesinger, H.; Buniatian, G. H.; Gleiter, C. H. The blockade of endothelin A receptor protects astrocytes against hypoxic injury: Common effects of BQ-123 and erythropoietin on the rejuvenation of the astrocyte population. Eur. J. Cell. Biol. 84:567-579; 2005.

18. Danielyan, L.; Mueller, L.; Proksch, B.; Kabisch, D.; Weller, M.; Wiesinger, H.; Buniatian, G. H.; Gleiter, C. H. Similar protective effects of BQ-123 and erythropoietin on survival of neural cells and generation of neurons upon hypoxic injury. Eur. J. Cell. Biol. 84:907-913; 2005.

19. Danielyan, L.; Schäfer, R.; Schulz, A.; Ladewig, T.; Lourhmati, A.; Buadze, M.; Schmitt, A. L.; Verleysdonk, S.; Kabisch, D.; Koeppen, K.; Siegel, G.; Proksch, B.; Kluba, T.; Eckert, A.; Köhle, C.; Schöneberg, T.; Northoff, H.; Schwab, M.; Gleiter, C. H. Survival, neuron-like differentiation and functionality of mesenchymal stem cells in neurotoxic environment: The critical role of erythropoietin. Cell Death Differ. 16:1599-1614; 2009.

20. Danielyan, L.; Schäfer, R.; von Ameln-Mayerhofer, A.; Bernhard, F.; Verleysdonk, S.; Buadze, M.; Lourhmati, A.; Klopfer, T.; Schaumann, F.; Schmid, B.; Koehle, C.; Proksch, B.; Weissert, R.; Reichardt, H. M.; van den Brandt, J.; Buniatian, G. H.; Schwab, M.; Gleiter, C. H.; Frey, 2nd, W. H. Therapeutic efficacy of intranasally delivered mesenchymal stem cells in a rat model of Parkinson disease. Rejuv. Res. 14:3-16; 2011.

21. Danielyan, L.; Schäfer, R.; von Ameln-Mayerhofer, A.; Buadze, M.; Geisler, J.; Klopfer, T.; Burkhardt, U.; Proksch, B.; Verleysdonk, S.; Ayturan, M.; Buniatian, G. H.; Gleiter, C. H.; Frey, 2nd, W. H. Intranasal delivery of cells to the brain. Eur. J. Cell. Biol. 88:315-324; 2009. 
22. Dhuria, S. V.; Hanson, L. R.; Frey, 2nd, W. H. Intranasal delivery to the central nervous system: Mechanisms and experimental considerations. J. Pharm. Sci. 99:1654-1673; 2010.

23. Donega, V.; van Velthoven, C. T. J.; Nijboer, C. H.; van Bel, F.; Kas, M. J. H. Intranasal mesenchymal stem cell treatment for neonatal brain damage: Long-term cognitive and sensorimotor improvement. PLoS One 8:e51253; 2013.

24. Ehrenreich, H.; Hinze-Selch, D.; Stawicki, S.; Aust, C.; Knolle-Veentjer, S.; Wilms, S.; Heinz, G.; Erdag, S.; Jahn, H.; Degner, D.; Ritzen, M.; Mohr,A.;Wagner, M.; Schneider, U.; Bohn, M.; Huber, M.; Czernik, A.; Pollmächer, T.; Maier, W.; Sirén, A. L.; Klosterkötter, J.; Falkai, P.; Rüther, E.; Aldenhoff, J. B.; Krampe, H. Improvement of cognitive functions in chronic schizophrenic patients by recombinant human erythropoietin. Mol. Psychiatry 12:206-220; 2007.

25. El Khoury, J.; Toft, M.; Hickman, S. E.; Means, T. K.; Terada, K.; Geula, C.; Luster, A. D. Ccr2 deficiency impairs microglial accumulation and accelerates progression of Alzheimer-like disease. Nat. Med. 13:432-438; 2007.

26. Fiala, M.; Liu, P. T.; Espinosa-Jeffrey, A.; Rosenthal, M. J.; Bernard, G.; Ringman, J. M.; Sayre, J.; Zhang, L.; Zaghi, J.; Dejbakhsh, S.; Chiang, B.; Hui, J.; Mahanian, M.; Baghaee, A.; Hong, P.; Cashman, J. Innate immunity and transcription of MGAT-III and Toll-like receptors in Alzheimer's disease patients are improved by bisdemethoxycurcumin. Proc. Natl. Acad. Sci. USA 104:12849-12854; 2007.

27. Finsen, B.; Sorensen, T.; Castellano, B.; Pedersen, E.; Zimmer, J. Leukocyte infiltration and glial reactions in xenografts of mouse brain tissue undergoing rejection in the adult rat brain: A light and electron microscopical immunocytochemical study. J. Neuroimmunol. 32:159-183; 1991.

28. Fransson, M.; Piras, E.; Burman, J.; Nilsson, B.; Essand, M.; Lu, B.; Harris, R. A.; Magnusson, P. U.; Brittebo, E.; Loskog, A. S. CAR/FoxP3-engineered T regulatory cells target the CNS and suppress EAE upon intranasal delivery. J. Neuroinflammation 9:112; 2012.

29. Frey, 2nd, W. H.; Liu, J.; Thorne, R. G.; Rahman, Y-E. Intranasal delivery of ${ }^{125}$ I-NGF to the brain via the olfactory route. In: Iqbal, K.; Mortimer, J.; Winblad, B.; Wisniewski, H., eds. Research advances in Alzheimer's Disease and related disorders. New York, NY: John Wiley \& Sons; 1995:329-335.

30. Gonzalez, F. F.; McQuillen, P.; Mu, D.; Chang, Y.; Wendland, M.; Vexler, Z.; Ferriero, D. M. Erythropoietin enhances long-term neuroprotection and neurogenesis in neonatal stroke. Dev. Neurosci. 29:321-330; 2007.

31. Grathwohl, S. A.; Kälin, R. E.; Bolmont, T.; Prokop, S.; Winkelmann, G.; Kaeser, S. A.; Odenthal, J.; Radde, R.; Eldh, T.; Gandy, S.; Aguzzi, A.; Staufenbiel, M.; Mathews, P. M.; Wolburg, H.; Heppner, F. L.; Jucker, M. Formation and maintenance of Alzheimer's disease beta-amyloid plaques in the absence of microglia. Nat. Neurosci. 12:1361-1363; 2009.

32. Gutiérrez-Fernández, M.; Rodríguez-Frutos, B.; RamosCejudo, J.; Teresa Vallejo-Cremades, M.; Fuentes B.; Cerdán, S.; Díez-Tejedor, E. Effects of intravenous administration of allogenic bone marrow- and adipose tissuederived mesenchymal stem cells on functional recovery and brain repair markers in experimental ischemic stroke. Stem Cell Res. Ther. 4:11; 2013.

33. Hawkes, C. A.; McLaurin, J. Selective targeting of perivascular macrophages for clearance of beta-amyloid in cerebral amyloid angiopathy. Proc. Natl. Acad. Sci. USA 106:12611266; 2009.

34. Hinze, A.; Stolzing, A. Microglia differentiation using a culture system for the expansion of mice non-adherent bone marrow stem cells. J. Inflamm. 9:12; 2012.

35. Hussain, A. A. Mechanism of nasal absorption of drugs. Prog. Clin. Biol. Res. 292:261-272; 1989.

36. Iwai, M.; Cao, G.; Yin, W.; Stetler, R. A.; Liu, J.; Chen, J. Erythropoietin promotes neuronal replacement through revascularization and neurogenesis after neonatal hypoxia/ ischemia in rats. Stroke 38:2795-2803; 2007.

37. Joyce, N.; Annett, G.; Wirthlin, L.; Olson, S.; Bauer, G.; Nolta, J. A. Mesenchymal stem cells for the treatment of neurodegenerative disease. Regen. Med. 5:933-946; 2010.

38. Kadota, T.; Shingo, T.; Yasuhara, T.; Tajiri, N.; Kondo, A.; Morimoto, T.; Yuan, W. J.; Wang, F.; Baba, T.; Tokunaga, K.; Miyoshi, Y.; Date, I. Continuous intraventricular infusion of erythropoietin exerts neuroprotective/rescue effects upon Parkinson's disease model of rats with enhanced neurogenesis. Brain Res. 1254:120-127; 2009.

39. Kahle, P. J.; Neumann, M.; Ozmen, L.; Müller, V.; Odoy, S.; Okamoto, N.; Jacobsen, H.; Iwatsubo, T.; Trojanowski, J. Q.; Takahashi, H.; Wakabayashi, K.; Bogdanovic, N.; Riederer, P.; Kretzschmar, H. A.; Haass, C. Selective insolubility of alpha-synuclein in human Lewy body diseases is recapitulated in a transgenic mouse model. Am. J. Pathol. 159:2215-2225; 2001.

40. Karussis, D.; Grigoriadis, S.; Polyzoidou, E.; Grigoriadis, N.; Slavin, S.; Abramsky, O. Neuroprotection in multiple sclerosis. Clin. Neurol. Neurosurg. 108:250-254; 2006.

41. Kitada, M.; Dezawa, M. Parkinson's disease and mesenchymal stem cells: Potential for cell-based therapy. Parkinsons Dis. 12:873706; 2012.

42. Koenigsknecht-Talboo, J.; Meyer-Luehmann, M.; Parsadanian, M.; Garcia-Alloza, M.; Finn, M. B.; Hyman, B. T. Rapid microglial response around amyloid pathology after systemic anti-Abeta antibody administration in PDAPP mice. J. Neurosci. 28:14156-14164; 2008.

43. Kozlowska, H. Transplantation of a novel human cord blood-derived neural-like stem cell line in a rat model of cortical infarct. Stem Cells Dev. 16:481-488; 2007.

44. Lappalainen, R. S.; Narkilahti, S.; Huhtala, T.; Liimatainen, T.; Suuronen, T.; Närvänen, A.; Suuronen, R.; Hovatta, O.; Jolkkonen, J. The SPECT imaging shows the accumulation of neural progenitor cells into internal organs after systemic administration in middle cerebral artery occlusion rats. Neurosci. Lett. 440:246-250; 2008.

45. Lee, H. J.; Suk, J. E.; Patrick, C.; Bae, E. J.; Cho, J. H.; Rho, S.; Hwang, D.; Masliah, E.; Lee, S. J. Direct transfer of alpha-synuclein from neuron to astroglia causes inflammatory responses in synucleinopathies. J. Biol. Chem. 285: 9262-9272; 2010.

46. Lee, J. K.; Jin, H. K.; Endo, S.; Schuchman, E. H.; Carter, J. E.; $\mathrm{Bae}$, J. S. Intracerebral transplantation of bone marrowderived mesenchymal stem cells reduces amyloid-beta deposition and rescues memory deficits in Alzheimer's disease mice by modulation of immune responses. Stem Cells 28:329-343; 2010.

47. Lee, S. T.; Chu, K.; Park, J. E.; Jung, K. H.; Jeon, D.; Lim, J. Y.; Lee, S. K.; Kim, M.; Roh, J. K. Erythropoietin improves memory function with reducing endothelial dysfunction and amyloid-beta burden in Alzheimer's disease models. J. Neurochem. 120:115-124; 2012. 
48. Liu, Y.; Walter, S.; Stagi, M.; Cherny, D.; Letiembre, M.; Schulz-Schaeffer, W. LPS receptor (CD14): A receptor for phagocytosis of Alzheimer's amyloid peptide. Brain 128:1778-1789; 2005.

49. Lochhead, J. J.; Thorne, R. G. Intranasal delivery of biologics to the central nervous system. Adv. Drug Deliv. Rev. 64:614-628; 2012.

50. Lomoio, S.; López-González, I.; Aso E.; Carmona, M.; Torrejón-Escribano, B.; Scherini, E.; Ferrer, I. Cerebellar amyloid- $\beta$ plaques: Disturbed cortical circuitry in A $\beta P P /$ PS1 transgenic mice as a model of familial Alzheimer's disease. J. Alzheimer's Dis. 31:285-300; 2012.

51. Louhrmati, A.; Buniatian, G. H.; Paul, C.; Verleydonk, S.; Buecheler, R.; Buadze, M.; Proksch, B.; Schwab, M.; Gleiter, C. H.; Danielyan, L. Age-dependent astroglial vulnerability to hypoxia and glutamate: The role for erythropoietin. PLoS One 8:e77182; 2013.

52. Maurice, T.; Mustafa, M. H.; Desrumaux, C.; Keller, E.; Naert, G.; de la C García-Barceló, M.; Rodríguez Cruz, Y.; Garcia Rodríguez, J. C. Intranasal formulation of erythropoietin (EPO) showed potent protective activity against amyloid toxicity in the A $\beta 25-35$ non-transgenic mouse model of Alzheimer's disease. J. Psychopharmacol. 26:1044-1057; 2013.

53. McKeon, R.; Schreiber, R.; Rudge, J.; Silver, J. Reduction of neurite outgrowth in a model of glial scarring following CNS injury is correlated with the expression of inhibitory molecules on reactive astrocytes. J. Neurosci. 11:3398$3411 ; 1991$

54. McLaurin, J.; Cecal, R.; Kierstead, M. E.; Tian, X.; Phinney, A. L.; Manea, M. Therapeutically effective antibodies against amyloid-beta peptide target amyloid-beta residues 4-10 and inhibit cytotoxicity and fibrillogenesis. Nat. Med. $8: 1263-1269 ; 2002$.

55. Neumann, M.; Kahle, P. J.; Giasson, B. I.; Ozmen, L.; Borroni, E.; Spooren, W.; Müller, V.; Odoy, S.; Fujiwara, H.; Hasegawa, M.; Iwatsubo, T.; Trojanowski, J. Q.; Kretzschmar, H. A.; Haass, C. Misfolded proteinase K-resistant hyperphosphorylated alpha-synuclein in aged transgenic mice with locomotor deterioration and in human alpha-synucleinopathies. J. Clin. Invest. 110:1429-1439; 2002.

56. Pendharkar, A. V.; Chua, J. Y.; Andres, R. H.; Wang, N.; Gaeta, X.; Wang, H.; De, A.; Choi, R.; Chen, S.; Rutt, B. K.; Gambhir, S. S.; Guzman, R. Biodistribution of neural stem cells after intravascular therapy for hypoxic-ischemia. Stroke 41:2064-2070; 2010.

57. Perry, V.; Andersson, P.; Gordon, S. Macrophages and inflammation in the central nervous system. Trends Neurosci. 16: 268-273; 1993.

58. Ramot, Y.; Steiner, M.; Morad, V.; Leibovitch, S.; Amouyal, N.; Cesta, M. F.; Nyska, A. Pulmonary thrombosis in the mouse following intravenous administration of quantum dot-labeled mesenchymal cells. Nanotoxicology 4:98-105; 2010.

59. Reitz, M.; Demestre, M.; Sedlacik, J.; Meissner, H.; Fiehler, J.; Kim, S. U.; Westphal, M.; Schmidt, N. O. Intranasal delivery of neural stem/progenitor cells: A noninvasive passage to target intracerebral glioma. Stem Cells Transl. Med. 1:866-873; 2012.

60. Saresella, M.; Marventano, I.; Calabrese, E.; Piancone, F.; Rainone, V.; Gatti, A.; Alberoni, M.; Nemni, R.; Clerici, M. A complex proinflammatory role for peripheral monocytes in Alzheimer's disease. J. Alzheimers Dis. 38:403-413; 2014.
61. Sargin, D.; El-Kordi, A.; Agarwal, A.; Müller, M.; Wojcik, S. M.; Hassouna, I.; Sperling, S.; Nave, K. A.; Ehrenreich, $\mathrm{H}$. Expression of constitutively active erythropoietin receptor in pyramidal neurons of cortex and hippocampus boosts higher cognitive functions in mice. BMC Biol. 9:27; 2011.

62. Simard, A. R.; Soulet, D.; Gowing, G.; Julien, J. P.; Rivest, $\mathrm{S}$. Bone marrow-derived microglia play a critical role in restricting senile plaque formation in Alzheimer's disease. Neuron 49:489-502; 2006.

63. Sinden, J. D.; Patel, S. N.; Hodges, H. Neural transplantation: Problems and prospects for therapeutic application. Curr. Opin. Neurol. Neurosurg. 5:902-908; 1992.

64. Spillantini, M. G.; Crowther, R. A.; Jakes, R.; Cairns, N. J.; Lantos, P. L. Filamentous alpha-synuclein inclusions link multiple system atrophy with Parkinson's disease and dementia with Lewy bodies. Neurosci. Lett. 251:205-208; 1998.

65. Steiner, B.; Roch, M.; Holtkamp, N.; Kurtz, A. Systemically administered human bone marrow-derived mesenchymal stem home into peripheral organs but do not induce neuroprotective effects in the MCAO-mouse model for cerebral ischemia. Neurosci. Lett. 513:25-30; 2012.

66. Stemberger, S.; Jamnig, A.; Stefanova, N.; Lepperdinger, G.; Reindl, M.; Wenning, G. K. Mesenchymal stem cells in a transgenic mouse model of multiple system atrophy: Immunomodulation and neuroprotection. PLoS One 6:e19808; 2011.

67. Thorne, R. G.; Pronk, G.; Padmanabhan, V.; Frey, 2nd, W. H. Delivery of insulin-like growth factor-I to the brain and spinal cord along olfactory and trigeminal pathways following intranasal administration. Neuroscience 127:481-496; 2004.

68. Town, T.; Laouar, Y.; Pittenger, C.; Mori, T.; Szekely, C. A.; Tan, J. Blocking TGF-beta-Smad2/3 innate immune signaling mitigates Alzheimer-like pathology. Nat. Med. 14:681$687 ; 2008$.

69. Tuszynski, M. H.; Gage, F. H. Bridging grafts and transient nerve growth factor infusions promote long-term central nervous system neuronal rescue and partial functional recovery. Proc. Natl. Acad. Sci. USA 92:4621-4625; 1995.

70. Tuszynski, M. H.; Thal, L.; Pay, M.; Salmon, D. P.; U, H. S.; Bakay, R.; Patel, P.; Blesch, A.; Vahlsing, H. L.; Ho, G. A phase 1 clinical trial of nerve growth factor gene therapy for Alzheimer disease. Nat. Med. 11:551-555; 2005.

71. van Velthoven, C. T.; Kavelaars, A.; van Bel, F.; Heijnen, C. J. Nasal administration of stem cells: A promising novel route to treat neonatal ischemic brain damage. Pediatr. Res. 68:419-422; 2010.

72. Walker, P. A.; Aroom, K. R.; Jimenez, F.; Shah, S. K.; Harting, M. T.; Gill, B. S.; Cox, Jr., C. S. Advances in progenitor cell therapy using scaffolding constructs for central nervous system injury. Stem Cell Rev. 5:283-300; 2009.

73. Wang, Y.; Yang, J.; Li, H.; Wang, X.; Zhu, L.; Fan, M.; Wang, X. Hypoxia promotes dopaminergic differentiation of mesenchymal stem cells and shows benefits for transplantation in a rat model of Parkinson's disease. PLoS One 8:e54296; 2013.

74. Wei, N.; Yu, S. P.; Gu, X.; Taylor, T. M.; Song, D.; Liu, X. F.; Wei, L. Delayed intranasal delivery of hypoxicpreconditioned bone marrow mesenchymal stem cells enhanced cell homing and therapeutic benefits after ischemic stroke in mice. Cell Transplant. 22:977-991; 2013.

75. Wu, S.; Li, K.; Yan, Y.; Gran, B.; Han, Y.; Zhou, F.; Guan, Y.; Rostami, A.; Zhang, G. Intranasal delivery of neural stem cells: A CNS-specific, non-invasive cell-based therapy for 
experimental autoimmune encephalomyelitis. J. Clin. Cell. Immunol. 4:142; 2013.

76. Xue, Y. Q.; Ma, B. F.; Zhao, L. R.; Tatom, J. B.; Li, B.; Jiang, L. X.; Klein, R. L.; Duan, W. M. AAV9-mediated erythropoietin gene delivery into the brain protects nigral dopaminergic neurons in a rat model of Parkinson's disease. Gene Ther. 17:83-94; 2010.

77. Yagi, H.; Soto-Gutierrez, A.; Parekkadan, B.; Kitagawa, Y.; Tompkins, R. G.; Kobayashi, N.; Yarmush, M. L. Mesenchymal stem cells: Mechanisms of immunomodulation and homing. Cell Transplant. 19:667-679; 2010.
78. Yang, B.; Migliati, E.; Parsha, K.; Schaar, K.; Xi, X.; Aronowski, J.; Savitz, S. I. Intra-arterial delivery is not superior to intravenous delivery of autologous bone marrow mononuclear cells in acute ischemic stroke. Stroke 44:3463-3472; 2013

79. Zaghi, J.; Goldenson, B.; Inayathullah, M.; Lossinsky, A. S.; Masoumi, A.; Avagyan, H.; Mahanian, M.; Bernas, M.; Weinand, M.; Rosenthal, M. J.; Espinosa-Jeffrey, A.; de Vellis, J.; Teplow, D. B.; Fiala, M. Alzheimer disease macrophages shuttle amyloid-beta from neurons to vessels: Contributing to amyloid angiopathy. Acta Neuropathol. 117:111-124; 2009. 